\title{
Internet na escola: possibilidade para a alfabetização informacional
}

\author{
Maria Conceição da Silva Linhares \\ mcslinhares@gmail.com \\ Universidade Federal de Sergipe, Brasil \\ Ronaldo Nunes Linhares \\ nuneslinhares.ronaldo8@gmail.com \\ Universidade Tiradentes Aracaju, Sergipe, Brasil \\ Juliana Silva Linhares \\ juliana linhares@unit.br \\ Universidade Tiradentes Aracaju, Sergipe, Brasil
}

Resumo: Este artigo analisa a contribuição das práticas pedagógicas com o uso das redes sociais e ferramentas da internet para a alfabetização informacional de alunos do ensino médio. A partir de autores como Gasque (2012), Cerveró (2007), Area (2006), Soares (2002) e Freire (1987), que ressaltam que saber usar a informação significa expressar-se com e a partir dela, numa abordagem criativa, de compreensão do que se lê, de articulação de palavras chaves, de conceitos e ideias a caminho da intertextualidade. Esse saber é valorativo na sociedade atual, adjetivada pelo aumento exponencial da informação, disponível em diversos formatos e linguagens através das tecnologias da informação e comunicação, dentre elas, a internet. A abordagem qualitativa na perspectiva da observação participante é a opção que melhor atende ao objeto desse estudo por considerar na sua análise, as relações entre os sujeitos e as mediações culturais, objetivadas pelos espaços e ferramentas da internet para acender a alfabetização informacional. Desenvolver práticas pedagógicas usando as redes sociais e ferramentas da internet para trabalhar a alfabetização informacional contribuem para uma vivência significativa com a informação.

Palavras chave: Alfabetização informacional; internet; práticas pedagógicas.

Internet en la escuela: posibilidad para la alfabetización informacional

Resumen; En este trabajo se analiza la contribución de las prácticas pedagógicas con el uso de herramientas de redes sociales y el Internet para la alfabetización informacional de los estudiantes de secundaria. Según autores como Gasque (2012), Cerveró (2007), Area (2006), Smith (2002) y Freire (1987), a sabiendas de cómo utilizar la información de los medios para expresarse y de él, un enfoque creativo, la comprensión de lo que leemos en conjunto palabras clave, conceptos e ideas sobre la manera de intertextualidad. Este conocimiento es evaluativa en la sociedad actual, adjetiva por el aumento exponencial de la información disponible en distintos formatos e idiomas dispositivo a través de la información y la comunicación, entre ellos, las tecnologías de Internet. El enfoque cualitativo en la perspectiva de la observación participante es la opción que mejor se adapte al objeto de este estudio al considerar en su análisis, las relaciones entre los sujetos y las mediaciones culturales, objetivadas por los espacios y herramientas de internet para iluminar la alfabetización informacional. Desarrollar prácticas pedagógicas que utilizan los medios sociales y herramientas de Internet para trabajar la alfabetización en información contribuye a una experiencia significativa con la información.

Palabras clave: Alfabetización en información; internet; las prácticas de enseñanza

Internet at school: possibility for information literacy 
Abstract: In this work the contribution of teaching practices using social networking tools and computer literacy of high school students the Internet is analyzed. According to authors like Gasque (2012), Cervero (2007) Area (2006), Smith (2002) and Freire (1987), knowing how to use the information and the means to express it, a creative approach, understanding of what we read in conjunction keywords, concepts and ideas on how to intertextuality. This knowledge is evaluative in today's society, adjective by the exponential increase of information available in various formats and languages device through information and communication, including Internet technologies. The qualitative approach in the perspective of participant observation is the option that the object of this study suits to consider in its analysis, the relationships between subjects and cultural mediations, objectified by Internet spaces and tools to illuminate computer literacy. Develop pedagogical practices using social media and Internet tools for computer literacy work contributes to a significant experience with information.

Keywords: Computer literacy; Internet; Pedagogy; Social networking

\section{Introdução}

Usar a informação a contento das demandas da sala de aula, para a realização de tarefas e resolução de problemas, são aspirações dos professores em relação a seus alunos. Saber usar a informação significa expressar-se com e a partir dela, numa abordagem criativa, de compreensão do que se lê, de articulação de palavras chaves, de conceitos e ideias a caminho da intertextualidade ${ }^{1}$.

Esse saber é valorativo na sociedade atual, adjetivada pelo aumento exponencial da informação, disponível em diversos formatos e linguagens através das tecnologias da informação e comunicação (TIC), dentre elas, a internet. Esta possui espaços, ferramentas e recursos convidativos a intervenção, seja pelas escolhas de busca, pela distribuição e produção da informação ou pela indução a comunicação.

O fluxo informacional e comunicacional no meio digital é constante, caótico, fluido e instável, por está em constante transformação e atualização pela demanda de interesses, posições e imposições que compõe uma rede de interconexões. Demanda que impõe de um lado, um ritmo de acesso segundo a lógica do capital, de consumo em forma de zapping, um movimento aligeirado, transversal à cognição e a experiência, sem deixar marcas efetivas ao conhecimento e à formação. E de outro, sob a imposição da cultura digital, a emergência de que os sujeitos, nativos dessa cultura desenvolvam competências para saber lidar com as informações.

\footnotetext{
${ }^{1}$ Refere-se a um movimento de associações cognitivas para fora do texto, de interconexão com outras leituras e informações. Nesse caso, representa a abrangência de associações cognitivas que o leitor poderá fazer com o texto.
} 
Um caminho para segunda proposição é a alfabetização informacional que prima pelo uso efetivo da informação, usando-a com consciência e referência ao objetivo proposto.

$\mathrm{Na}$ escola, um dos caminhos viáveis para tornar os alunos competentes em informação através da alfabetização informacional é desenvolver práticas pedagógicas em que a informação seja trabalhada sob diferentes proposições na trilha da aprendizagem, como usar a internet e as redes sociais como ambiente de interação e produção. É nesta perspectiva que este trabalho se inscreve com o objetivo de analisar a contribuição de práticas pedagógicas com o uso das redes sociais e ferramentas da internet para a alfabetização informacional de alunos do ensino médio, numa escola da rede pública, no estado de Sergipe-Brasil.

\section{Perspectivas da internet para alfabetização informacional}

Os ambientes, recursos e linguagens da internet são espaços prenhes de fazeres e saberes, mas que se situam no campo das possibilidades, no se, como imperativo às realizações, como perspectiva do se houver, empreendimento, comprometimento, disponibilidade, acesso, orientação, principalmente, nos espaços formais de aprendizagem, como a escola, em que as práticas objetivam agregar valor à formação de alunos e professores.

Articulação necessária para fomentar aprendizagens a partir da relação com a informação, desde o acesso, passando pela busca, escolha, reflexão à produção; processo cognitivo inicial e potencial à alfabetização, como processo para a formação de leitores que compreendem o que leem, atribuindo sentido e articulações com outros textos, informações e linguagens.

Articulações necessárias segundo Cerveró (2007), não somente para a formação de um leitor com capacidade de agregar valor no ato da leitura, ao saber discriminar, priorizar, valorizar e assimilar, mas imprescindível na sociedade do conhecimento em que a leitura adquire uma nova dimensão, ler se converte num ato variado que não se limita ao livro, mas a diferentes tipos de leitura e em diferentes suportes.

Acomoda-se nesse contexto, a alfabetização informacional compreendida por Dudziak (2003, p. 29) como processo contínuo de internalização de fundamentos conceituais, atitudinais e de habilidades necessário à compreensão e interação permanente com o universo informacional e sua dinâmica, de modo a proporcionar um aprendizado ao longo da vida.

Aprendizado que requer a mobilização de conhecimentos, habilidades e atitudes relacionadas ao universo informacional, como a competência leitora, no sentido de saber manipular os meios tecnológicos, seja digital ou analógico para descobrir como e onde 
encontrar a informação e com ela realizar ações cognitivas próprias da manipulação e processamento, como interpretação, associação, análise e síntese.

A alfabetização informacional mediada por diferentes meios proporciona o conhecimento de múltiplas representações da informação e do conhecimento, como é o caso da internet caracterizada por uma rede de informações fluida, dinâmica, interconectada por ambientes e ferramentas com especificidades na apresentação textual e no modo de produção/interação. O Chat, por exemplo, exige rapidez na escrita para dá fluidez a comunicação, o Twitter, exige poder de síntese devido ao limite de 140 caracteres para edição de texto e assim, com todos os outros.

Penetrar nesses espaços e ferramentas implica descobrir novas formas de organização e processamento da informação e nesse ínterim, o desenvolvimento de habilidades necessárias para a cultura digital e a alfabetização informacional. Combinação necessária para a vida numa sociedade caracterizada da informação (CASTELLS, 2000).

Contexto que na visão de Enox e Walker (1992), a alfabetização informacional na educação formal é uma necessidade prática e uma obrigação moral, pois nos permite expressar, explorar e compreender o fluxo de ideias entre indivíduos e grupos de pessoas num ambiente tecnológico em constante mudança. E segundo a American Library Association (1989), a pessoa alfabetizada deve ser capaz de reconhecer quando a informação é necessária e ter a capacidade de localizar, avaliar e usar efetivamente a informação necessária.

Competências necessárias para uma experiência eficaz com a informação e por isso, tão almejadas na escola pública brasileira, com complexidades diversas, dentre elas, altos índices de alfabetismo funcional ${ }^{2}$, como mostram os dados revelados pelo Indicador de Alfabetismo Funcional- INAF. Em 2011, 47\% dos brasileiros entre 15 e 64 anos apresentavam um nível básico ${ }^{3}$ de leitura, escrita e matemática. Em 2001, esse nível representava 34\% dos entrevistados. Deficiência demonstrada, por exemplo, nas atividades de leitura e escrita, por alunos que não conseguem identificar no contexto do texto, a informação que necessita para responder a questão, a problematização, muitas vezes por lerem pausadamente, em processo de silabação como tentativa à decodificação, e que abstraem da leitura as pausas e

\footnotetext{
${ }^{2}$ Segundo INAF - é considerada analfabeta funcional a pessoa que, mesmo sabendo ler e escrever um enunciado simples, como um bilhete, por exemplo, ainda não tem as habilidades de leitura, escrita e cálculo necessárias para participar da vida social em suas diversas dimensões: no âmbito comunitário, no universo do trabalho e da política.

${ }^{3}$ Segundo INAF - as pessoas classificadas neste nível podem ser consideradas funcionalmente alfabetizadas, pois já leem e compreendem textos de média extensão, localizam informações mesmo que seja necessário realizar pequenas inferências, leem números na casa dos milhões, resolvem problemas envolvendo uma sequência simples de operações e têm noção de proporcionalidade. Mostram, no entanto, limitações quando as operações requeridas envolvem maior número de elementos, etapas ou relações.
} 
entonações, necessárias à compreensão e que deformam o texto e o pensamento por não dominarem a tecnologia do sistema de escrita e por esta via, a compreensão da informação.

Para Soares (2002; 2013), a alfabetização é um processo de codificação e decodificação dos fonemas em grafemas e vice-versa, mas também de compreensão/expressão de significados por meio do código escrito. Aquisição importante para a imersão do sujeito na cultura, pela via da compreensão e participação. Mas para a autora, (2013 p. 29) não basta simplesmente "saber ler e escrever": dos indivíduos já se requer não apenas que dominem a tecnologia do ler e do escrever, mas também que saibam fazer uso dela, incorporando-a a seu viver, transformando-se assim seu "estado", como consequência do domínio dessa tecnologia (grifos da autora).

Domínio necessário para a manipulação efetiva do código escrito para criar significados, estabelecer categorias, critérios de análise para avaliar e validar as informações.

Situação que converge com a dinâmica da sociedade atual bombardeada de informações e em que grande parte é disponibilizada pelas Tecnologias da Informação e Comunicação, como a internet. E devido a sua configuração de espaço aberto, interativo e de fluidez da informação, apresenta mudanças culturais nesse domínio, como novas práticas sociais de leitura e escrita.

De acordo com Area e Pessoa (2012), pautados em Bauman (2006), que discute a metáfora do líquido para caracterizar as mudanças socioculturais da cultura digital - o tempo atual - é um fluido de produção de informação e conhecimento instável, em permanente mudança e em constante transformação. A informação, portanto, não tem permanência, estabilidade, é líquida, escorre no fluido de mudanças e atualização da informação.

Requer na visão Area e Pessoa (2012, p. 15) uma alfabetização ${ }^{4}$ que deve representar um processo de desenvolvimento de uma identidade como sujeito no território digital, que se caracterize pela apropriação significativa das competências intelectuais, sociais e éticas necessárias para interatuar com a informação e para recriá-la de um modo crítico e emancipador.

Representação de desenvolvimento de quem participa efetivamente dos processos de interação, como interlocutor da informação no processo de comunicação e produção, e, portanto, de quem possui segundo Soares $(2002,145)$, "o estado ou condição de quem exerce

\footnotetext{
${ }^{4}$ La alfabetización debe representar un proceso de desarrollo de una identidad como sujeto em El territorio digital, que se caracterice por la apropiación significativa de las competencias intelectuales, sociales y éticas necesarias para interactuar con La información y para recrear la de un modo crítico y emancipador.
} 
efetivamente práticas sociais de leitura e escrita (grifos da autora) - processo denominado pela autora de letramento".

Seja pela concepção de alfabetização, de Area e Pessoa (2012), Area (2006) ou de letramento, por Soares $(2002,2013)$ são aportes importantes para o enfrentamento do desenvolvimento de competências postas e impostas pelo imperativo do consumo da informação e ainda, de um perfil de sujeito que esteja preparado para o uso das interfaces e linguagens digitais para agir concomitante às mutações da sociedade na contemporaneidade, selecionando, avaliando e produzindo informações a partir das referências dos acontecimentos locais e globais.

São exigências que ultrapassam a simples codificação e decodificação do signo escrito, é a etapa inicial, mas não suficiente para a alfabetização no contexto informacional, cuja finalidade, segundo Gasque (2012, p. 32), é a adaptação e a socialização dos indivíduos na sociedade da aprendizagem. Visto que esta possibilita: i) determinar a extensão das informações necessárias; ii) acessar a informação de forma efetiva e eficientemente; iii) avaliar criticamente a informação e a suas fontes; iv) incorporar a nova informação ao conhecimento prévio; v) usar a informação de forma efetiva para atingir objetivos específicos; vi) compreender os aspectos econômico, legal e social do uso da informação, bem como acessá-la e usá-la ética e legalmente.

O domínio do contexto relacional com a informação, com a leitura e com a escrita, aliada a alfabetização informacional requer uma alfabetização na perspectiva Freireana (1987; 2005), para além das técnicas mecânicas de escrever e ler, mas sim, de "aprender a dizer a palavra", exercício de expressão e reflexão do eu no mundo e o mundo no eu. Ação dialógica necessária para dominar as significações e representações da cultura vigente por meio de uma alfabetização continuada e integrada aos espaços e ferramentas digitais para a interlocução do sujeito com a cultura, suas representações e linguagens.

Assim, na visão de Freire (2005, p. 21), a alfabetização não é um jogo de palavras, é a consciência reflexiva da cultura, a reconstrução crítica do mundo humano, a abertura de novos caminhos, o projeto histórico de um mundo comum, a bravura de dizer a sua palavra.

Delineia um processo de mudança mediante a conscientização acerca dos problemas cotidianos, locais, mas interconectados com os globais, num processo de ressignificação de saberes, de sentidos, com vistas à conscientização do indivíduo quanto ao seu papel como sujeito social e cultural.

Práxis que formata a preocupação com a formação do sujeito que usa a informação para mediar a sua percepção e intervenção na realidade em que vive. Mas como desenvolver nos alunos de ensino médio uma alfabetização como prática reflexiva sobre/com a informação 
na vivência dos espaços e ferramentas virtuais? E como desenvolver estratégias para a formação de um leitor e escritor competente segundo o aporte da alfabetização informacional?

O levantamento dessas questões nos impulsiona a afirmar que desenvolver práticas pedagógicas usando as redes sociais e ferramentas da internet para trabalhar a alfabetização informacional contribui para uma vivência significativa com a informação, no sentido de atribuir sentido ao que se lê, quando se identifica o que, o como e o para quê da informação, funciona como guia a um posicionamento reflexivo.

É caminho, portanto, para desenvolver a competência leitora dos alunos que estão no ensino fundamental e médio com dificuldades de leitura e escrita, de compreender o que leem e de se expressar. É caminho também para a inserção dos alunos na cultura digital para além do entretenimento, como meio de aprendizagem.

A busca, a leitura, a escrita, a publicação e a interação são mecanismos que favorecem, de modo geral, a alfabetização compreendida como ato de aprender a ler e a escrever e de modo singular, a alfabetização informacional, que para além do exercício da leitura e da escrita, envolve também o tratamento da informação, o que confere significado a mesma. Mecanismos disponíveis nas janelas e espaços textuais das redes sociais e ferramentas da internet, de configuração hipertextual, envolvida por textos, imagens, sons, animação, vídeo, o que condiciona novos modos de fazer, de ler e escrever.

A escola precisa se apropriar das vantagens das configurações desses espaços para desenvolver práticas pedagógicas que contribuam com a alfabetização informacional, a fim de melhorar a competência leitora e escritora dos alunos.

\section{Implementação de práticas pedagógicas com o uso da internet e redes sociais para alfabetização informacional}

As tecnologias da informação e comunicação - TIC caracterizadas pela convergência de linguagens, celeridade na busca da informação e ubiquidade no processo de comunicação, contribuem para fomentar espaços plurais e descentralizados de aprendizagem.

No espaço escolar, impulsiona uma mudança de paradigma no processo educativo a começar pela ruptura da sala de aula como único lugar formal do fazer pedagógico para uma sala de aula que se amplia que não tem lugar comum, que está em qualquer lugar, porque está no espaço virtual, podendo ser acessada para novas descobertas e para o exercício do fazer/aprender na sala de informática, em casa, na praça, no clube, onde conexão encontrar e quando possibilidade tiver. Nesse contexto, tempo e espaço se flexibilizam, se expandem para 
além de uma sala de aula situada geograficamente em algum lugar, com uma rotina de atividades, de compromissos cronometrados em horas-aula e se comprimem diante da simultaneidade de ações e conexões entre elas.

Impulsiona também uma mudança na postura do professor, detentor da informação, do conhecimento para o de mediador, o problematizador da informação e de processos educativos como meio para a construção do conhecimento. Muda também a do aluno, passivo, receptor da informação para uma postura ativa no processo, que busca a informação, investiga os conteúdos curriculares e o que quer aprender. Comportamento e posicionamento suscitado pela dinâmica da cultura digital, que requer para a prática da mediação com a informação, competências informacionais.

Novas atitudes, posturas, relações e articulações, conclamam o fazer e o ser da escola, do aluno, do professor, no contexto de mediações com as TIC e, em particular, da internet e as redes sociais.

\subsection{Facebook: conexões para o ENEM}

As redes sociais e, em particular, o Facebook são espaços públicos, abertos a colaboração e prenhes de saberes e fazeres para mediar a aprendizagem, como é o caso da ferramenta grupo, espaço delimitado pelo envio de convites aos participantes com possibilidades de publicação de textos, imagens e vídeos, de discussão em tempo real e em tempo posterior, permite criar e agendar eventos, carregar e tirar fotos para criar álbum, a construção colaborativa no Google docs e criar perguntas anônimas. São recursos que possibilitam expandir as informações trabalhadas na sala de aula, sejam para solicitar a busca de conceitos, informações sobre um determinado autor, um poema para ilustrar a aula, uma notícia, um debate, proposições potenciais para a aprendizagem.

Potencialidades que subsidiou a utilização da ferramenta Grupo, do Facebook pelos alunos das turmas do 10 , 20 e 30 anos do ensino médio, cerca de 90 alunos, do turno vespertino, do Colégio Estadual Presidente Emílio Garrastazu Médici, em Aracaju-SergipeBrasil, sob a mediação da professora de Língua Portuguesa, idealizadora da proposta e com a participação dos professores das outras disciplinas das referidas turmas nas discussões das postagens na rede, como espaço de aprendizagem colaborativa e interdisciplinar com vistas à leitura, a interpretação, a publicação e a discussão de assuntos intra e extraclasse, tendo como foco, o ENEM - Exame Nacional do Ensino Médio.

A proposta foi subsidiada pela abordagem qualitativa na perspectiva da observação participante por considerar na sua análise, as relações entre os sujeitos e as mediações 
culturais, objetivadas pelos espaços e ferramentas da internet para acender a alfabetização informacional. E também por permitir acompanhar as singularidades do fazer no cotidiano da escola, as mutações na dinâmica das realizações pedagógicas, de construções e reconstruções de significados por alunos e professores.

Essa opção subsidiou o mergulho na realidade social dos jovens alunos do ensino médio, numa interlocução com os fazeres, os saberes e os conhecimentos imbricados na vivência da ferramenta grupo, do Facebook para analisar essas relações como possibilidades de aprendizagem para o ENEM e para a alfabetização informacional.

Para tanto, se fez necessário discutir a necessidade da alfabetização informacional para a vivência na sociedade atual; compreender que a convivência em espaços públicos, como o Facebook precisa ser regida por normas e valores; oportunizar o desenvolvimento da leitura e da escrita e utilizar técnicas de redação para apresentação e discussão da informação.

Objetivos necessários para as discussões e reflexões realizadas durante o desenvolvimento das atividades na sala de aula e na sala de informática desde a apresentação da proposta, de seus objetivos e etapas até a execução da mesma, enfatizando a potencialidade da rede como espaço de aprendizagem interdisciplinar e colaborativo, em que todos ensinam e aprendem (coisas boas e ruins) e também sobre a necessidade da alfabetização informacional para a vivência e convivência na sociedade atual, cercada por informações exponencialmente distribuídas pelos meios digitais, capital para o conhecimento e para a realização do ENEM. Desdobramento para considerações sobre a necessidade de saber lidar com a informação, no sentido de saber encontrar, selecionar e avaliar de acordo com a necessidade da pesquisa, dos objetivos e problematizações.

Além da proposição dos objetivos, as atividades foram guiadas pela estratégia da escuta pelos professores e reflexão para novas descobertas das possibilidades educativas a partir do que os alunos fazem e sabem com o uso das redes sociais, especificamente, do Facebook e o que pensam e potencializam para o contexto escolar.

Escuta que revelou que as ações e os saberes conquistados pelo uso frequente e otimismo no fazer nas redes sociais se situam para além do entretenimento em direção a interação, a comunicação e a aprendizagem. Revelações que eclodiram nas falas dos alunos e precisaram ser registrados para além da memória dos professores. Para garantir o registro do uso do Facebook pelos alunos e suas opiniões sobre o uso da mesma no ambiente escolar foi aplicado um questionário sondagem semiestruturado no Google docs com as seguintes questões: Você usa as redes sociais no seu dia a dia? Quais as que você usa? Você acha que o professor deve levar as redes sociais para a sala de aula? Por quê? Em sua opinião, quais os recursos/ferramentas do facebook que podem ser trabalhados em sala de aula? Por quê? 
Ter conhecimento dos fazeres e saberes dos jovens alunos com o uso das redes sociais digitais e suas potencialidades na escola é o recorte que apresentamos neste texto e norte para a finalidade da proposta que foi de criar condições para que os alunos desenvolvessem habilidades informacionais e digitais a partir de situações de aprendizagem baseadas nos conteúdos curriculares e extracurriculares.

Situações em que buscar e usar a informação disponibilizada na internet era necessário para ampliar o entendimento a partir de outros contextos, de outros pontos de vista, o que convergia para o desenvolvimento de habilidades para saber, por exemplo, buscar a informação, identificando e selecionando as fontes para as reflexões necessárias às respostas solicitadas.

Contexto que conduziu o trabalho com informações e orientações para a alfabetização informacional na perspectiva da inclusão digital, com discussões sobre direitos autorais, usando técnicas de pesquisa com buscadores, e-book, dicionários e enciclopédias para comparar diferentes pontos de vistas e adotar critérios para organizar e avaliar as informações e sobre estratégias de leitura e interpretação de texto, como por exemplo, identificar palavraschaves, ideia principal e conceitos.

\subsection{A percepção dos alunos sobre as redes}

Dos alunos que participaram da proposta e responderam ao questionário, 43 (88\%) afirmaram que usam as redes sociais em seu dia a dia. Numa relação de redes apresentadas no questionário (Facebook, Twitter, Blog, Orkut, MySpace, Linkedin e outras), a grande maioria, 45 (92\%) afirmam usar o Facebook.

Todos os alunos acham que o professor deve levar as redes sociais para a sala de aula. Afirmam que essas redes são espaços de comunicação importantes, que os alunos dominam, conhecem e usam muito em seu dia a dia e podem aproximar professor e aluno, desperta o interesse do aluno e torna a aula mais interessante.

Para um destes alunos,

\footnotetext{
"a sala de aula ganha uma extensão, que pode ser acessada a qualquer hora em qualquer lugar, servindo de ponto de encontro entre o professor e o aluno".

"melhor pra passar os assuntos do Colégio quando algum aluno falta".
}

Percepção fecunda de ampliação da sala de aula e de aprendizagem nas/pelas redes digitais, para além do tempo de aula presencial, possibilitada pela dinâmica do fazer/aprender 
nas redes, convergente à participação, suscitam possibilidades diversas, inclusive, de interação e aproximação entre professores e alunos.

A compreensão da importância do uso em sala aparece na maioria das contribuições, tanto em relação ao acesso da informação atualizada, elemento que aparece em mais de $40 \%$ das contribuições, como para uma compreensão inversa ao que se discute sobre o uso exclusivo da rede para bate-papo. Apontam que com essas redes ampliam-se as possibilidades de interação e produção colaborativa do conhecimento. Numa destas contribuições quatro alunos destacam que,

"As redes sociais não era só para bater papo, mas sim para discutir outros assuntos, como os das atividades escolares".

"Porque acaba facilitando e induzindo ainda mais os alunos para assuntos escolares".

"pois é um meio de obtermos conhecimento, pois o ser humano está apto a absorver informações, além de contribuir para a interação dos alunos com determinados assuntos".

"porque além de interagir de uma forma diferente e nova com os alunos, faz com que venhamos perceber o quanto as redes sociais é importante não apenas para bater papo, mais para dividirmos novos conhecimentos juntos".

Os alunos também percebem a resistência de alguns professores. No entanto, uma das escritas destaca que,

"Enquanto alguns professores ainda resistem bravamente em manter sua aversão aos computadores e à internet e insistem na interação tradicional professor-aluno, outros já começam a experimentar a relação extra-classe virtual por meio das redes sociais on-line".

Quando foram questionados sobre quais os recursos/ferramentas do Facebook podem ser trabalhados em sala de aula e por quê? Apenas um afirma que não há utilidade do Facebook na educação. A maioria dos respondentes afirma que o grupo é o principal recurso. A fala abaixo traduz bem esta referência ao grupo e justifica o por que.

"O grupo mesmo porque é reservado e vc pode expor ideias para todos da escola, pode usar o grupo para varias formas diferentes como vídeos, fotos, reportagens, enquete etc..Uma ideia boa é os alunos ler, saber de um assunto e ir para as ruas saber as opiniões das pessoas sobre aquele assunto que está sendo falado ou discutido e gravar um vídeo para o grupo, isso é uma forma de interação e é uma forma diferente e divertida de aprender. A professora lone fez isso uma vez e eu achei muito bom e acho realmente que deveria voltar a colocar em prática e divulgar para toda a escola para que o ensino diversificado e fora da sala de aula seja cada vez mais comum entre professores e alunos". 
Na análise das opiniões, o diálogo, a autoria, o compartilhamento e a interação contribuem com as discussões de assuntos estudados em sala de aula, potencializados pelo uso da ferramenta bate-papo; pela busca de vídeos-aula em páginas online; jogos educacionais; aplicativos; álbuns de fotos; eventos e conferências. Cabe aqui destacar também as observações sobre os grupos fechados como espaços comuns de interesses e sobre a importância de que as postagens sejam curtas e interessantes para o grupo, facilitando a leitura e a participação por todos.

Concepções adquiridas pelo imperativo do consumo dos serviços e informações disponibilizadas nas redes digitais, imperativo de consumo constante condicionando necessidades de relações, de entretenimentos e informações. Compreensões pela imbricação dos sujeitos nas redes: joga, ouve música, vê e produz vídeos, cria álbuns, publica, compartilha informações, entre outros serviços e nesse movimento otimiza e vislumbra a rede como espaço de produção, de interação e de aprendizagem.

Imperativo que condiciona um perfil de sujeito que saiba lidar com a informação nesses meios. Estar preparado para o uso das interfaces e linguagens digitais significa agir concomitante às mutações da sociedade na contemporaneidade, selecionando, avaliando e produzindo informações a partir das referências dos acontecimentos locais e globais.

\section{Considerações finais}

No contexto da sociedade atual, da mediação da informação como mercadoria de troca, de produção, de interação e de conhecimento nos permite construir uma reflexão positiva de práticas pedagógicas com o uso da internet e das redes sociais, na perspectiva da alfabetização informacional, como potencializadoras da manipulação efetiva da informação, em direção a aprendizagem.

Analisar e compreender o que se lê é direcionamento para que alunos e professores se posicionem quanto à informação como interlocutores e protagonistas nos processos de produção e de interação. São, portanto, mediações e construções necessárias à formação do sujeito atual, pois identificar e analisar a informação são exercícios necessários para os processos de ensinar e aprender nos espaços digitais. Assim, ao ler um texto na internet para a resolução de um problema e para atingir um determinado objetivo faz-se necessário questionar o aluno sobre as estratégias que ele usou para compreender o que leu e buscar a solução do problema.

São proposições importantes para além de codificar e decodificar o signo escrito, para a o desenvolvimento de competências para a alfabetização informacional. 


\section{Referências}

AMERICAN LIBRARY ASSOCIATION. Presidential Committee on Information Literacy. (1989). Final Report, Chicago: ALA. Disponível em http://www.ala.org/acrl/nili/ilit1st.html

AREA, M. La enseñanza universitaria en tiempos de cambio: el papel de las bibliotecas en la innovación educativa. En: IV Jornadas CRAI de la Red de Bibliotecas Universitarias (REBIUN). Experiencias en el ámbito de la organización y la convergencia de servicios. Universidad de Burgos, 10-12 mayo 2006.2 Disponible http://www.rebiun.org/export/docReb/manuel_area.pdf . ; PESSOA, Teresa. De lo sólido a lo líquido: las nuevas alfabetizaciones ante los câmbios culturales de la Web 2.0. Comunicar, v. 19, n. 38, p. 13-20, 2012.

CASTELLS, Manuel. A sociedade em rede. 3a ed.. São Paulo: Paz e Terra. 2000.

CUEVAS-CERVERÓ, Aurora Cuevas. Lectura, alfabetizacion em informacion y biblioteca escolar. Espanha: Trea, 2007.

DUDZIAK, Elisabeth Adriana. Information literacy: princípios, filosofia e prática. Ciência da Informação, Brasília, v. 32, n. 1, p. 23-35, jan./abr. 2003.

ENOX, M. F.; WALKER, M. L. Information literacy: challenge for the future.

International Journal of Information and Library Research, v. 4, n. 1, p. 1-18, 1992.

FREIRE, Paulo. Pedagogia do oprimido. 17. ed. Rio de Janeiro: Paz e Terra, 1987. . Pedagogia do oprimido. 49. ed. Rio de Janeiro: Paz e Terra, 2005.

GASQUE, Kelley Cristine Gonçalves Dias. Letramento Informacional: pesquisa, reflexão e aprendizagem. Brasília: Faculdade de Ciência da Informação / Universidade de Brasília, 2012.

SOARES, MAGDA. Novas práticas de leitura e escrita: letramento na cibercultura. Educação e Sociedade, Campinas, v. 23, n. 81, p. 143-160, dez. 2002. Disponível em: <http://www.cedes.unicamp.br. Acesso em: 22 ago 2014.

MAGDA, Soares. Alfabetização e Letramento. 6ạ Ed. São Paulo: Contexto, 2013.

Recebido/Recibido/Received: 2015-05-04

Aceitado/Aceptado/Accepted: 2015-05-29 